\title{
Annealing-Induced Modifications in Physicochemical and Optoelectronic Properties of Ag-Doped Nanostructured CdS Thin Films
}

\author{
Vidya S. Taur, Rajesh A. Joshi, and Ramphal Sharma \\ Thin Film and Nanotechnology Laboratory, Department of Physics, Dr. Babasaheb Ambedkar Marathwada University, \\ Aurangabad 431004, India \\ Correspondence should be addressed to Vidya S. Taur, vidutaur@gmail.com and Ramphal Sharma, rps.phy@gmail.com
}

Received 25 February 2012; Revised 6 May 2012; Accepted 14 May 2012

Academic Editor: David Lee Phillips

Copyright () 2012 Vidya S. Taur et al. This is an open access article distributed under the Creative Commons Attribution License, which permits unrestricted use, distribution, and reproduction in any medium, provided the original work is properly cited.

\begin{abstract}
The Ag-doped nanostructured CdS thin films are grown by simple, cost effective chemical ion exchange technique at room temperature on ITO-coated glass substrate. These as grown thin films are annealed at 100, 200, 300, and $400^{\circ} \mathrm{C}$ in air atmosphere for 1 hour. To study the effect of annealing on physicochemical and optoelectronic properties, these as grown and annealed thin films are characterized for structural, compositional, morphological, optical, and electrical properties. X-ray diffraction (XRD) pattern reveals polycrystalline nature of these thin films with increase in crystallite size from 6.4 to $11.2 \mathrm{~nm}$, from XRD the direct identification of $\mathrm{Ag}$ doping in $\mathrm{CdS}$ thin films cannot be judged, while shift in characteristics peak position of CdS is observed. The Raman spectrum represents increase in full width at half maxima and intensity of characteristic peak, confirming the material modification upon annealing treatment. Presence of Cd, Ag, and S in energy dispersive X-ray analysis spectra (EDAX) confirms expected elemental composition in thin films. Scanning electron microscopy (SEM) images represent grain growth and agglomeration upon annealing. Red shift in optical absorbance strength and energy band gap values from 2.28 to $2.14 \mathrm{eV}$ is obtained. $I-V$ response obtained from as grown and annealed thin films shows an enhancement in photosensitivity from $72 \%$ to $96 \%$ upon illumination to $100 \mathrm{~mW} / \mathrm{cm}^{2}$ light source.
\end{abstract}

\section{Introduction}

Nanostructured CdS thin films are the promising compounds for various industrial and household applications because of its potential physicochemical and optoelectronic properties such as wide energy band gap $(\mathrm{Eg}=2.42 \mathrm{eV})$, n-type conductivity, and high absorbance coefficient [1, 2]. CdS thin films are generally used as a window layer material associated with p-type conductivity, absorber layer for heterojunction solar cell applications $[3,4]$. However, the high resistivity of CdS thin film limits the output values of such heterostructure, therefore to reduce the resistivity and produce the desired property $\mathrm{CdS}$ thin films, an $\mathrm{Ag}$ doping is carried out $[5,6]$. The specific stoichiometry, surface morphology, crystalline quality, and nanostructured properties of Ag-doped CdS thin films make it potential material for solar cell and sensor applications. Therefore, the investigation of Ag-doped nanostructured CdS thin films is of critical importance for development of applicable device, therefore considering the multiple applications of these thin films number of research groups have prepared it by various methods. But considering the requirement of sensor, that is, stoichiometry, surface morphology, crystallinity and production cost, and so forth, the chemical bath deposition method is more useful. This technique is most inexpensive, suitable for synthesis of uniform and large area deposition. The films grown by this technique are generally polycrystalline, pin hole free, and stoichiometric [7]. Hence in utilization of Ag-doped nanostructured CdS thin films for optoelectronic applications the crystalline quality, surface morphology provides the scope for future research, therefore to improve these physicochemical and optoelectronic properties, postdeposition treatment such as annealing in air or swift heavy ion irradiation can be 
performed, but considering the cost as an issue, annealing in air is an affordable and useful technique for providing economically viable devices [8-10].

Therefore considering the wide application of Ag-doped CdS thin films, in the present work we have deposited Ag-doped CdS thin films by cost-effective chemical route at room temperature and the effect of annealing at 100, $200,300,400^{\circ} \mathrm{C}$ on physicochemical and optoelectronic properties has been studied and discussed.

\section{Experimental Details}

The nanostructured thin films of Ag-doped CdS thin films are prepared in two stages by using simple, cost effective chemical bath deposition method. The preparation process parameters of these thin films such as chemical concentration, molarities, $\mathrm{pH}$, reaction temperature, reaction time are optimized by repeating the experiment for multiple times till obtaining the good quality thin film. In first stage CdS thin films are deposited by chemical bath deposition method on conducting ITO-coated glass substrates using $0.02 \mathrm{M}$ cadmium sulphate $\left(\mathrm{CdSO}_{4}\right)$ and $0.02 \mathrm{M}$ thiourea $\left(\mathrm{CS}\left(\mathrm{NH}_{2}\right)_{2}\right)$ as a source of $\mathrm{Cd}^{2+}$ and $\mathrm{S}^{2-}$ ions, respectively. The equimolar concentration of these two reagents mixed in a beaker and the reaction carried for $1 \mathrm{~h}$ at controlled minimum low temperature of $80^{\circ} \mathrm{C}$ at $\mathrm{pH} \sim 11$ maintained by addition of excessive ammonia to the reactant mixture. Three drops of TEA (triethanol amine) are added to this reaction mixture to prevent the metal oxide formation. The $\mathrm{CdS}$ thin film formation mechanism proceeds as a function of solubility product of $\mathrm{Cd}$ and S ions, respectively. The film formation depends on the ionic distribution of the metal and chalcogenide sources. The film deposition takes place when ionic product exceeds solubility product (IP > SP) of the reactant. The thin film growth occurs as a result of induction of CdS ions to active site on ITO substrate followed by multiple nucleations to result in the formation of CdS thin film. The yellowish orange color appearance at the substrate surface confirms completion of reaction. The chemical reaction mechanism involved in formation of $\mathrm{CdS}$ can be represented as:

$$
\begin{gathered}
\mathrm{Cd}^{2+}+4 \mathrm{NH}_{3}{ }^{+} \longrightarrow \mathrm{Cd}\left(\mathrm{NH}_{3}\right)_{4}{ }^{2+}, \\
\mathrm{Cd}\left(\mathrm{NH}_{3}\right)_{4}{ }^{2+}+\mathrm{S}^{2-} \longrightarrow \mathrm{CdS} \downarrow+4 \mathrm{NH}_{3} \uparrow .
\end{gathered}
$$

In next stage these as deposited $\mathrm{CdS}$ thin films are used for Ag doping by chemical bath deposition at room temperature using $1 \% \mathrm{AgNO}_{3}$ solution prepared in distilled water. For Ag doping the CdS thin films are dipped in $\mathrm{AgNO}_{3}$ solution for 10 second [11]. These as grown Ag-doped CdS thin films are annealed at $100,200,300$, and $400^{\circ} \mathrm{C}$ in air atmosphere.

These as grown and annealed, Ag-doped nanostructured CdS thin films are characterized for structural, compositional, morphological, optical, and electrical properties. The structural properties are studied using X-ray diffraction pattern (XRD) obtained on Bruker AXS, German (D8 Advanced) diffractometer in scanning range $20-60^{\circ}(2 \theta)$

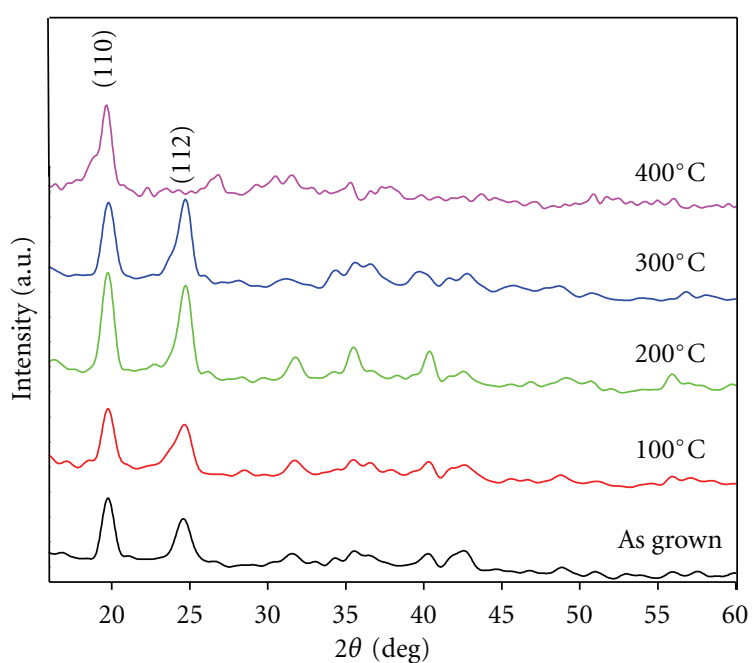

FIGURE 1: XRD pattern obtained from as grown and annealed, Ag doped nanostructured CdS thin films prepared by cost effective chemical route at room temperature.

using CuK $\alpha$ radiation having $1.5406 \AA$ wavelength. The Raman spectrum is measured using Raman spectrometer Renishaw model In-via Raman microscope using Argon ion LASER excitation of $514 \mathrm{~nm}$ ( $5 \mathrm{~mW}$ power) over the range 300 to $2100 \mathrm{~cm}^{-1}$. The elemental composition and surface morphology are studied with the help of energy dispersive X-rays analysis (EDAX) spectra and scanning electronic microscopy (SEM) obtained from JEOL-JSM6360. The optical characterization performed using UV-Vis spectrophotometer Perkin Elmer, Lambda-25 in absorbance mode as a function of wavelength in 400 to $1100 \mathrm{~nm}$ range. The photovoltaic response measured using current voltage $(I-V)$ characteristics under dark and illumination to $100 \mathrm{~mW} / \mathrm{cm}^{2}$ light source using Lab equip. model 2004 interfaced with computer.

\section{Results and Discussion}

3.1. X-Ray Diffraction (XRD) Pattern. The XRD pattern of as grown and annealed Ag-doped CdS thin films are represented in Figure 1, the presence of low intensity and multiple peaks in XRD pattern indicates that the thin films are polycrystalline in nature and consist of coarsely fine grains. The characteristics of (110) and (112) peaks observed in the XRD pattern correspond for CdS material, while upon Ag doping, no clear characteristics peak for Ag is observed in the XRD pattern, but a shift in peak position of CdS is observed when compared with JCPDS data card 02-0563, which indicates that Ag might have been immersed into the matrix of CdS nanoparticles [12].

When XRD pattern of annealed thin films is studied, it is observed that the peak intensity and full width at half maxima (FWHM) of (110) and (112) planes increase. Hence enhancement in these peaks is the significance of postdeposition annealing treatment and indicates improvement in the crystallinity of the thin films. The average crystallite size of as grown and annealed thin films calculated using 


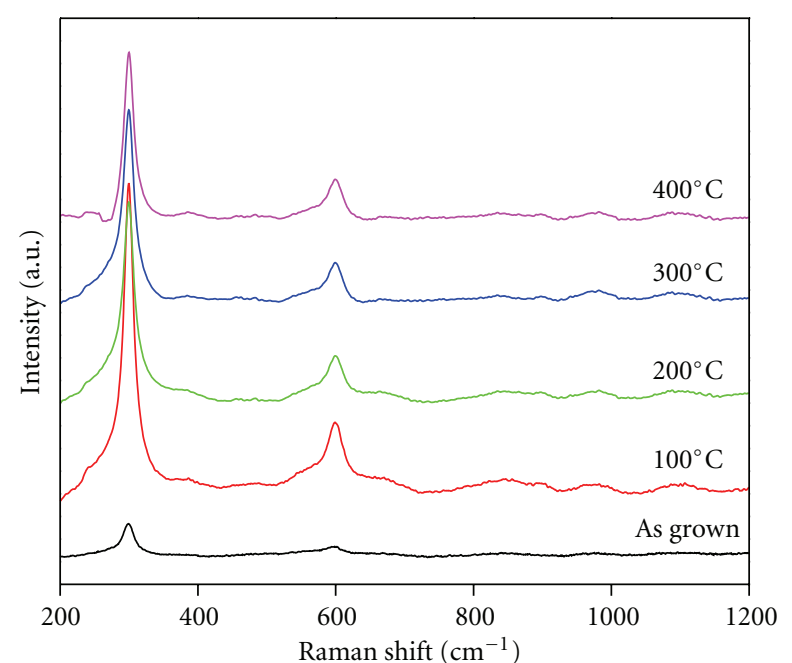

Figure 2: Raman spectra of as grown and annealed, Ag-doped nanostructured CdS thin films prepared by cost-effective chemical route at room temperature.

the Scherer formula is found to be 6.4, 7.1, 8.9, 10.6 and $11.2 \mathrm{~nm}$, respectively [13]. This increase in crystallite size can be correlated to annealing-induced disorders in Agdoped CdS thin films, as the large number of crystallites are present on the substrate, it is supposed that when annealing treatment is provided, the energy is absorbed by these crystalline, thereby they start coalescing with each other to form bigger crystallites, in other way it can be defined as melting and resolidification of crystallites which is called as polygonization. Therefore such high-energy induction reduces the strain in crystallites which is related to the structural deformations and disorders. Even upon annealing it is considered that the segregation of $\mathrm{Ag}^{+}$ions may induce considerable distortion near the grain boundaries due to larger ionic radii of $\mathrm{Cd}^{2+}(0.151 \mathrm{~nm})$ than $\mathrm{Ag}^{+}(0.122 \mathrm{~nm})$ ions, therefore such distortion may provide route or space for fast mass transportation and growth of particle size $[2,14]$.

3.2. Raman Spectra. The annealing-induced modifications observed from XRD pattern can also be confirmed by Raman spectra, obtained from as grown and annealed Ag-doped CdS thin films as represented in Figure 2. From the figure, peak observed at $\sim 303 \mathrm{~cm}^{-1}$ and $600 \mathrm{~cm}^{-1}$ represents Agdoped CdS thin films, while upon annealing, enhancement in intensity and FWHM of these peaks are observed which may be related to material modifications and increase in the density of lattice defect in thin films [12]. These defect induces stress in thin film which became center for photogenerated charge trapping [13].

3.3. Compositional Analysis. Figure 3 represents the energy dispersive X-ray (EDAX) spectra obtained from Ag-doped nanostructured CdS thin films for elemental composition analysis. The observation of peak corresponding to $\mathrm{Cd}$, $\mathrm{S}$, and $\mathrm{Ag}$ in the EDAX spectrum confirms Ag doping in

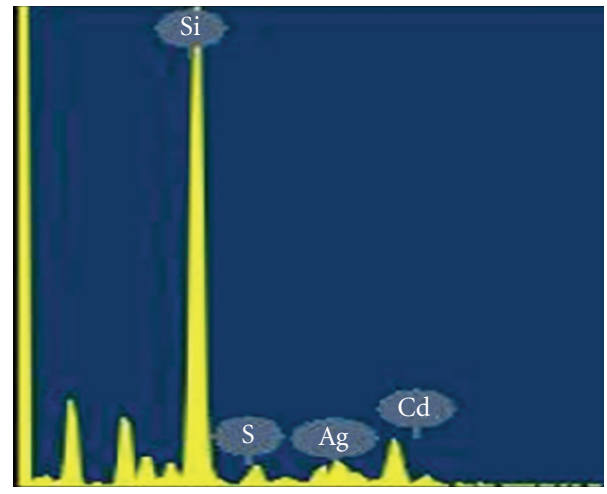

FIgURE 3: EDAX spectra obtained from as grown Ag doped nanostructured CdS thin films prepared by cost effective chemical route at room temperature.

CdS thin films, as such obtained elements confirm expected chemical composition in thin film.

3.4. Scanning Electron Microscopy (SEM). Figures 4(a), 4(b), 4(c), 4(d), and 4(e) represent the SEM images of as grown and $100,200,300,400^{\circ} \mathrm{C}$ annealed, Ag-doped CdS thin films, respectively. From Figure 4(a) it can be seen that Ag-doped CdS thin films have uniform grain distribution over the substrate surface, as the annealing treatment is provided it starts expanding the grains in stages like in SEM image of $100^{\circ} \mathrm{C}$ annealed thin films, grains look like being expanded at their positions, for $200^{\circ} \mathrm{C}$ some grains melted down, for $300^{\circ} \mathrm{C}$ the grain boundaries are about to disappear to form bigger grains and finally at $400^{\circ} \mathrm{C}$ recrystallization occurs since polygonization process involves exchange of energy (absorption and desorption) by crystallite therefore by this phenomenon, the grains melt down by high energy and instantly it again resolidified to form larger grains. This could be related to the fact that the grains are made up of small grains which on providing the heat treatment may be coalescing thereby the grain boundaries melt down and these coalesced grains may unite together to form big grain. These large grains can be very useful since interface defect are associated with them which may enhance the performance by photo-generated charge trapping [15].

3.5. Optical Characteristics. Annealing treatment to Agdoped CdS thin films may affect the probable electronic transitions in the material which can be monitored by studying the optical properties of these thin films. Figure 5 represents the optical absorbance spectra of as grown and annealed Ag-doped nanostructured CdS thin films. From the Figure 5, it can be seen that the optical absorbance strength decreases as the annealing temperature is increased, may be due to variation in physicochemical properties such as crystallite size, surface morphology, and compositional modifications up to certain extent $[15,16]$. Annealing provides possibility for ionic displacement in materials which can create large number of lattice defect like ionic vacancies, and so forth, these defect can act as trap centers and affect the optical absorbance. Therefore, decrease in optical band 


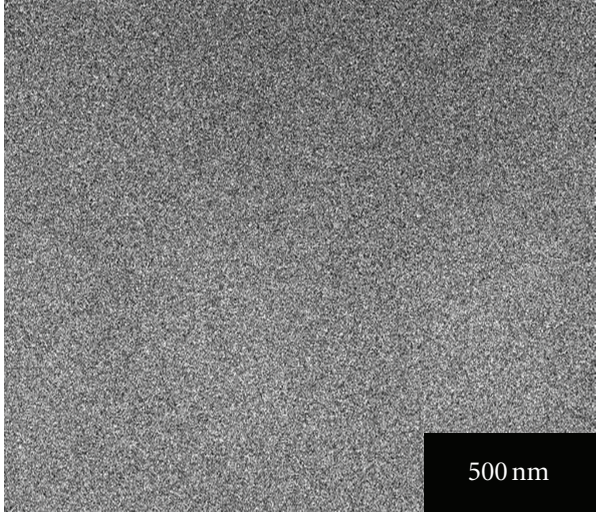

(a)

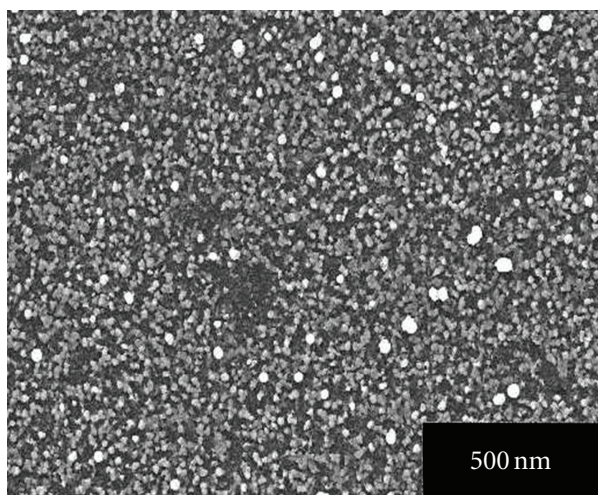

(c)

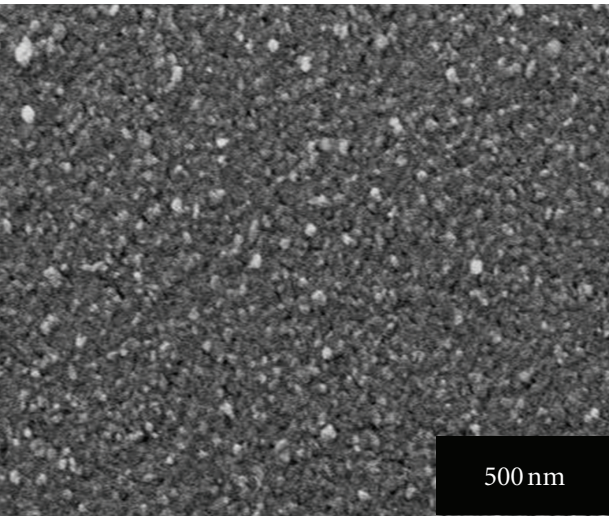

(b)

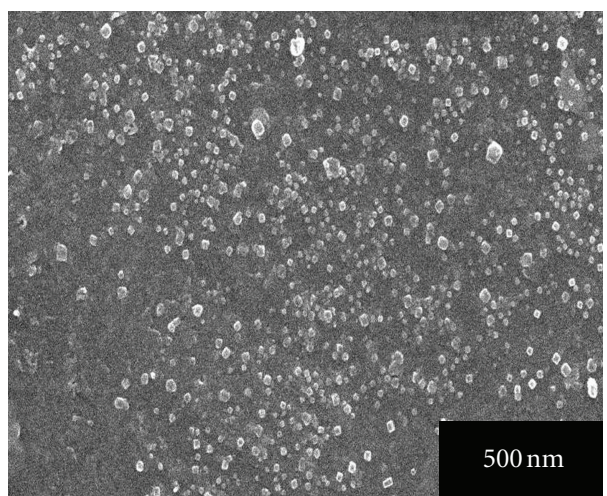

(d)

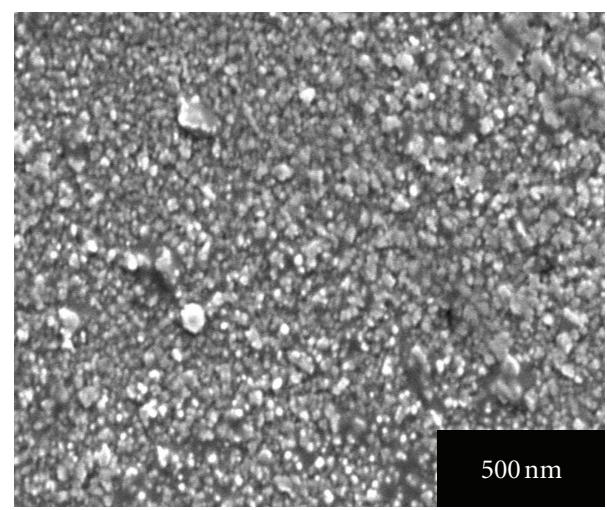

(e)

Figure 4: SEM images obtained from (a) as grown and (b) $100^{\circ} \mathrm{C}$, (c) $200^{\circ} \mathrm{C}$, (d) $300^{\circ} \mathrm{C}$, and (e) $400^{\circ} \mathrm{C}$ annealed, Ag-doped nanostructured CdS thin films.

strength can be primarily associated with defect-induced band tailing due to creation of localized energy states near the band edge [17].

The net effect of this absorbance spectra can be well understand by the classical relation connecting the absorption coefficient $\alpha$ and optical band gap Eg by

$$
\alpha h \nu=A(h v-\mathrm{Eg})^{n},
$$

where, $A$ is probability parameter for transition, $h v$ incident photon energy, $n$ is transition coefficient and Eg and energy band gap value which can be estimated from plot between $(\alpha h \nu)^{2}$ verses $(h v)$ as shown in Figure 6. From graph it can be seen that upon annealing, energy band gap values decrease which may be due to defect-induced band tailing, creation of impurity states, donor level degeneracy, and so forth. In this case, donor level degeneracy and disorder-induced band tailing are supposed to be the main cause for decrease in energy band gap (as mentioned in Table 1), because when annealing temperature is provided to the thin films it is gained by almost all the atoms of the material thereby due to thermal vibrations the atoms may have been displaced from their original positions and hence by colliding among 


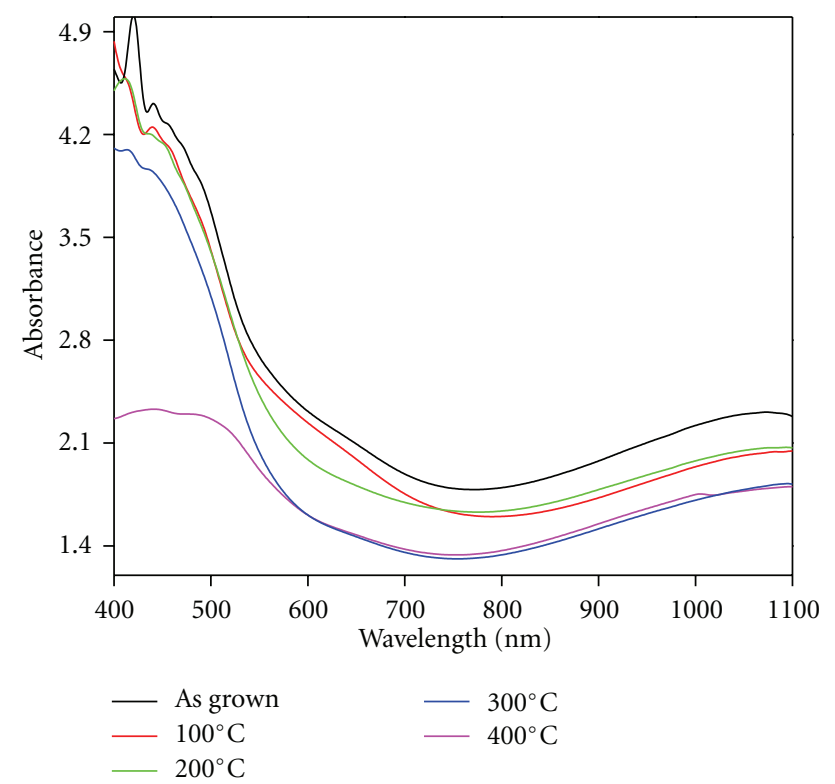

FIGURE 5: Plot of optical absorbance verses wavelength obtained for as grown and annealed Ag-doped nanostructured CdS thin films.

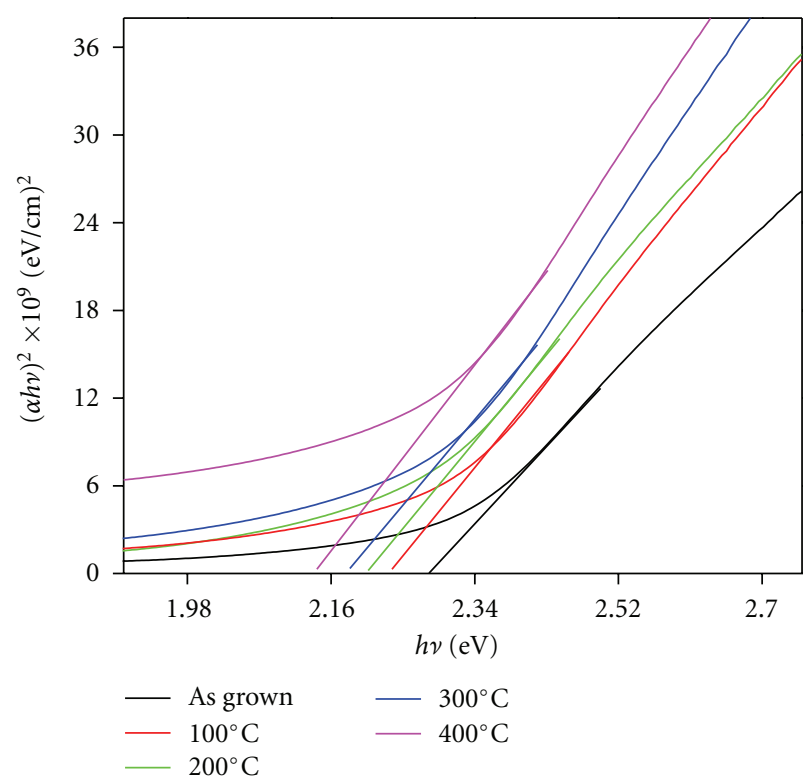

Figure 6: The energy band gap plot between $(\alpha h \nu)^{2}$ verses $h \nu(\mathrm{eV})$ for as grown and annealed, Ag-doped nanostructured CdS thin films.

themselves they create vacancies, interstitials, and so forth [13]. These defects can act as trapping centers and affect energy band gap [2].

3.6. Electrical Measurements. Annealing may significantly change the electrical properties, such as resistivity, charge carrier concentrations, and $I-V$ response of the thin films. The density of charge carrier concentration in as grown and annealed thin films is calculated using Vander Pauw technique at room temperature under dark conditions. The density of carrier concentration and charge mobility are observed to be increased from $5.7 \times 10^{17} \mathrm{~cm}^{-3}$ to 6.3 $\times 10^{19} \mathrm{~cm}^{-3}$ and $75.23 \mathrm{~cm}^{2} / \mathrm{Vs}$ to $83.78 \mathrm{~cm}^{2} / \mathrm{Vs}$, while the electrical resistivity measured using two probe techniques is observed to be decreasing from 2.79 to $1.2 \Omega \mathrm{cm}$ for as grown to annealed thin films, respectively.

Figures $7(\mathrm{a})$ and $7(\mathrm{~b})$ represent $I-V$ response of the as grown and annealed thin films under dark and illumination to $100 \mathrm{~mW} / \mathrm{cm}^{2}$ light source indicating an increase in photosensitivity of the thin films. The photosensitivity is calculated using the following formula:

$$
S(\%)=\left(\frac{R_{d}-R_{l}}{R_{l}}\right)
$$

where, $R_{d}$ and $R_{l}$ are the resistance under dark and illumination condition. From calculation it is observed that upon annealing the photosensitivity increases from 72 to $96 \%$. The observed rise in photosensitivity upon annealing treatment may be due to generation of defect states, improvements in crystallinity which acts as deep trap levels to capture the photo-generated charge carrier. Generally, for any p-type semiconductor, the intrinsic photosensitivity mainly depends on photo-excited charge carriers, that is, electrons. Upon annealing there exist impurity defect states in the material which forms recombination centers and trapping centers in the energy gap of the materials [18]. Upon illuminations to light the free electron-hole pairs get generated which are trapped by these recombination and trapping centers, so these electron hole pair cannot move freely before recombining with oppositely charged species, that is, either excited electrons or hole. An electron is excited from the valence band to the conduction band by absorbing light with energy equal to or greater than the band gap of the material, leaving holes in the valence band. The holes may follow a series of capture and emission processes before they are recombined with electrons. Such trapping, emission, and recombination of charge carriers lead to variation in the carrier concentration of the thin films and thereby result in photosensitivity enhancements.

\section{Conclusions}

From the above study it can be concluded that the Agdoped CdS thin films can be grown easily by simple, cost effective chemical route. The annealing treatment proves to be useful for physicochemical and optoelectronic modifications. XRD pattern shows an enhancement in crystallite size from 6.4 to $11.2 \mathrm{~nm}$, Raman spectra confirms the material modification and SEM shows grain growth through polygonization process. Elemental composition analyzed using the EDAX confirms the stoichiometry of the thin film. Decrease in optical absorbance strength and energy band gap shows defect-induced charge transportations and the photosensitivity enhancement is observed from 72 to $96 \%$ upon annealing treatment. Finally it can be 
TABle 1: The parameters of physicochemical and optoelectronic characteristics of as grown and annealed thin films of Ag doped nanostructured CdS prepared by cost effective chemical route at room temperature.

\begin{tabular}{lccccccc}
\hline Sr. No. & Sample & $D(\mathrm{~nm})$ & $\mathrm{Eg}(\mathrm{eV})$ & $n\left(\mathrm{~cm}^{-3}\right)$ & $\mu\left(\mathrm{cm}^{2} / \mathrm{Vs}\right)$ & $\rho(\Omega \mathrm{cm})$ & $S(\%)$ \\
\hline$(01)$ & As grown & 6.4 & 2.28 & $5.7 \times 10^{17}$ & 75.23 & 72 \\
$(02)$ & $100^{\circ} \mathrm{C}$ & 7.1 & 2.23 & $9.2 \times 10^{17}$ & 78.54 & 79 & 2.18 \\
$(03)$ & $200^{\circ} \mathrm{C}$ & 8.9 & 2.21 & $4.3 \times 10^{18}$ & 79.69 & 1.97 \\
$(04)$ & $300^{\circ} \mathrm{C}$ & 10.6 & 2.18 & $8.1 \times 10^{18}$ & 81.13 & 83 \\
$(05)$ & $400^{\circ} \mathrm{C}$ & 11.2 & 2.14 & $6.3 \times 10^{19}$ & 83.78 & 92 \\
\hline
\end{tabular}

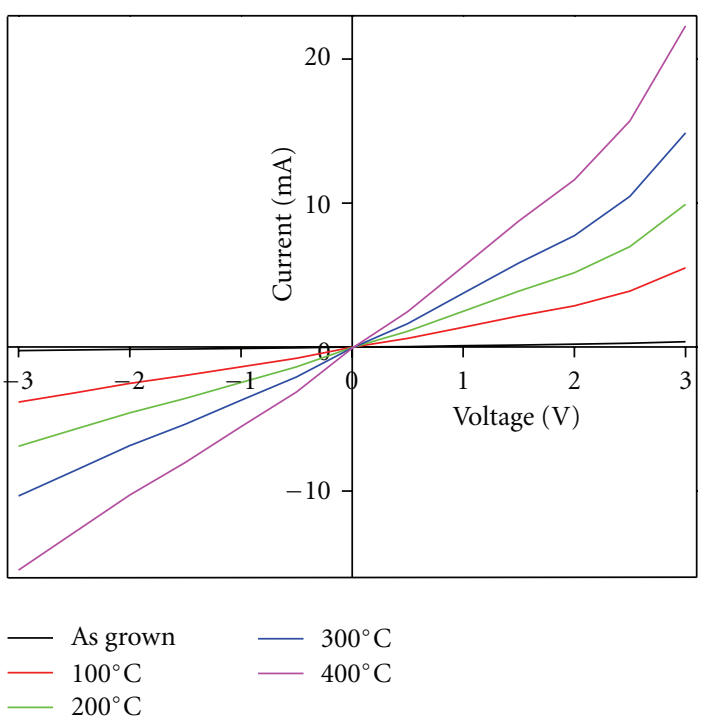

(a)

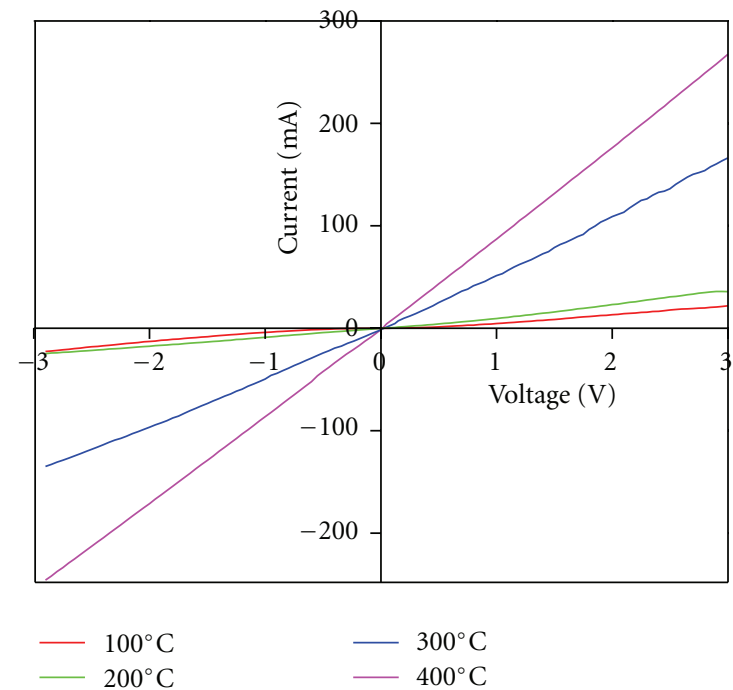

(b)

FIGURE 7: $I-V$ response of as grown and annealed thin films of Ag-doped nanostructured CdS under (a) dark and (b) illumination to $100 \mathrm{~mW} / \mathrm{cm}^{2}$ light source.

concluded that postdeposition treatment like air annealing helps in improving physicochemical as well as optoelectronic properties.

\section{Research Highlights}

Ag doping in nanostructured CdS thin films can be achieved by cost-effective chemical route.

Air annealing improves physicochemical and optoelectronic properties of these thin films.

$400^{\circ} \mathrm{C}$ annealed Ag-doped CdS thin films improve photosensitivity from 72 to $96 \%$.

\section{Acknowledgments}

The authors are thankful to The Head of Department of Physics, Dr. Babasaheb Ambedkar Marathwada University, Aurangabad for providing the laboratory facility and Dr. Anil V. Ghule, Assistant Professor, Department of Nanotechnology, Dr. Babasaheb Ambedkar Marathwada University, Aurangabad for helpful discussion.

\section{References}

[1] V. Biligin, S. Kose, F. Atay, and I. Akyuz, "The effect of substrate temperature on the structural and some physical properties of ultrasonically sprayed CdS films," Materials Chemistry and Physics, vol. 94, no. 1, pp. 103-108, 2005.

[2] S. Chandramohan, T. Strache, S. N. Sarangi, R. Sathyamoorthy, and T. Som, "Influence of implantation induced Nidoping on structural, optical, and morphological properties of nanocrystalline CdS thin films," Materials Science and Engineering B, vol. 171, no. 1-3, pp. 16-19, 2010.

[3] R. A. Joshi, A. Ghosh, V. S. Taur et al., "Nanostructured $p$-CuIn ${ }_{3} \mathrm{Se}_{3} / n$-CdS heterojunction engineered using simple wet chemical approach at room temperature for photovoltaic application," Materials Chemistry and Physics, vol. 127, no. 12, pp. 191-196, 2011.

[4] N. Romeo, A. Bosio, and A. Romeo, "An innovative process suitable to produce high-efficiency $\mathrm{CdTe} / \mathrm{CdS}$ thin-film 
modules," Solar Energy Materials and Solar Cells, vol. 94, no. 1, pp. 2-7, 2010.

[5] V. M. Bhuse, "Chemical bath deposition of Hg doped CdSe thin films and their characterization," Materials Chemistry and Physics, vol. 91, no. 1, pp. 60-66, 2005.

[6] I. D. Desnica-Frankovic, U. V. Desnica, A. Stötzler, and M. Deicher, "Study of microscopic mechanisms of electrical compensation of donors in $\mathrm{CdS}$ by fast diffusors $(\mathrm{Cu}, \mathrm{Ag}$, or Au)," Physica B, vol. 273-274, pp. 887-890, 1999.

[7] J. R. Mann, N. Vora, and I. L. Repins, "In situ thickness measurements of chemical bath-deposited CdS," Solar Energy Materials and Solar Cells, vol. 94, no. 2, pp. 333-337, 2010.

[8] V. S. Taur, R. A. Joshi, A. V. Ghule, and R. Sharma, "Effect of annealing on photovoltaic characteristics of nanostructured $p$ ${ }_{2} \mathrm{~S} / n$-CdS thin film," Renewable Energy, vol. 38, pp. 219-223, 2012.

[9] A. S. A. C. Diniz, "The effects of various annealing regimes on the microstructure and physical properties of ITO $\left(\mathrm{In}_{2} \mathrm{O}_{3}: \mathrm{Sn}\right)$ thin films deposited by electron beam evaporation for solar energy applications," Renewable Energy, vol. 36, no. 4, pp. 1153-1165, 2011.

[10] R. Sathyamoorthy, S. Chandramohan, P. Sudhagar, D. Kanjilal, D. Kabiraj, and K. Asokan, "Structural and photoluminescence properties of swift heavy ion irradiated CdS thin films," Solar Energy Materials and Solar Cells, vol. 90, no. 15, pp. 2297-2304, 2006.

[11] A. Gautam and S. Ram, "Preparation and thermomechanical properties of Ag-PVA nanocomposite films," Materials Chemistry and Physics, vol. 119, pp. 266-271, 2010.

[12] J. Ma, G. Tai, and W. Guo, "Ultrasound-assisted microwave preparation of Ag-doped CdS nanoparticles," Ultrasonics Sonochemistry, vol. 17, no. 3, pp. 534-540, 2010.

[13] H. Khallaf, G. Chai, O. Lupan, L. Chow, S. Park, and A. Schulte, "Characterization of gallium-doped CdS thin films grown by chemical bath deposition," Applied Surface Science, vol. 255, no. 7, pp. 4129-4134, 2009.

[14] S. T. Kuo, W. H. Taun, J. Sheih, and S. F. Wang, "Effect of Ag on the microstructure and electrical properties of $\mathrm{ZnO}$," Journal of the European Ceramic Society, vol. 27, no. 16, pp. 4521-4527, 2007.

[15] A. Cortes, H. Gómez, R. E. Marotti, G. Riveros, and E. A. Dalchiele, "Grain size dependence of the bandgap in chemical bath deposited CdS thin films," Solar Energy Materials and Solar Cells, vol. 82, no. 1-2, pp. 21-34, 2004.

[16] M. Thambidurai, N. Muthukumarasamy, S. Agilan et al., "Studies on optical absorption and structural properties of Fe doped CdS quantum dots," Solid State Sciences, vol. 12, no. 9, pp. 1554-1559, 2010.

[17] M. H. Yükselici, C. Allahverdi, and H. Athalin, "Zinc incorporation into CdTe quantum dots in glass," Materials Chemistry and Physics, vol. 119, pp. 218-221, 2010.

[18] A. Kumar and V. Chaudhary, "Optical and photophysical properties of Ag/CdS nanocomposites-an analysis of relaxation kinetics of the charge carriers," Journal of Photochemistry and Photobiology A, vol. 189, pp. 272-279, 2007. 


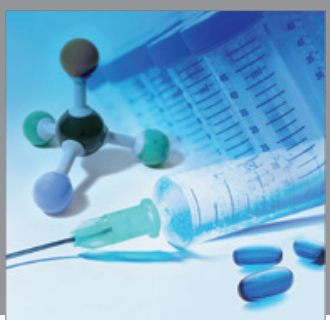

International Journal of

Medicinal Chemistry

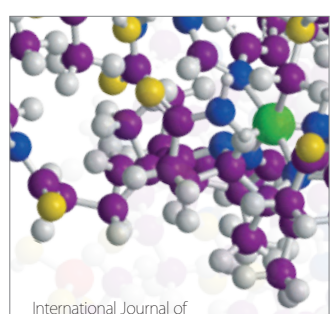

Carbohydrate Chemistry

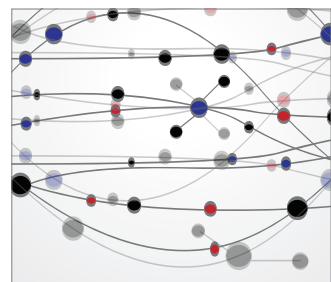

The Scientific World Journal
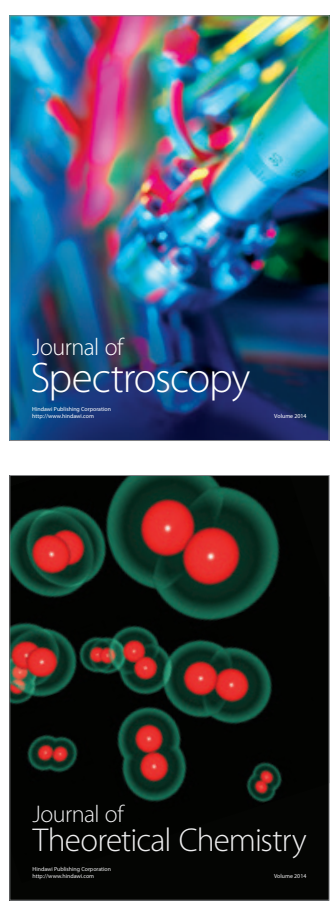
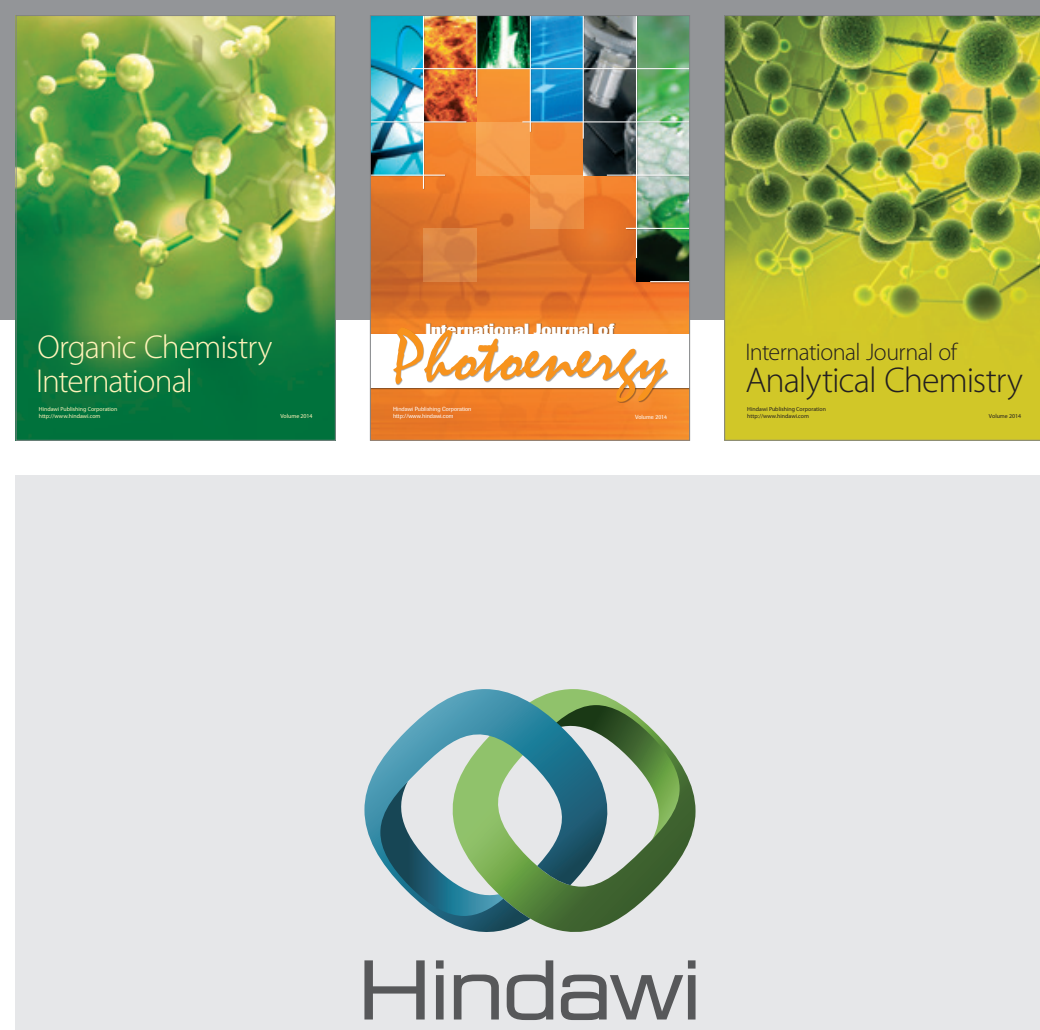

Submit your manuscripts at

http://www.hindawi.com
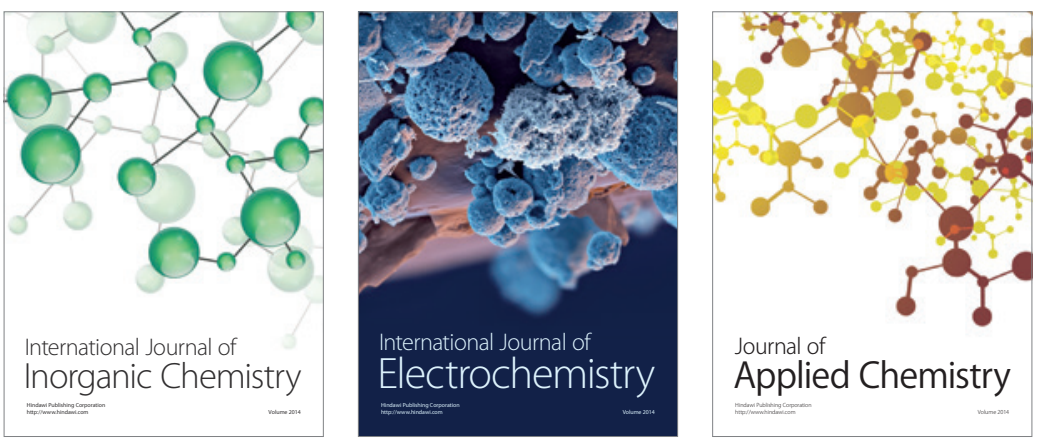

Journal of

Applied Chemistry
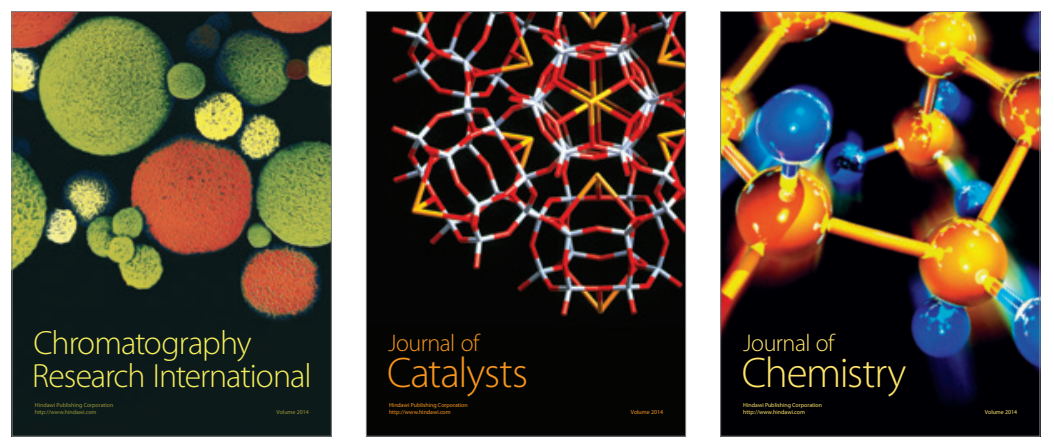
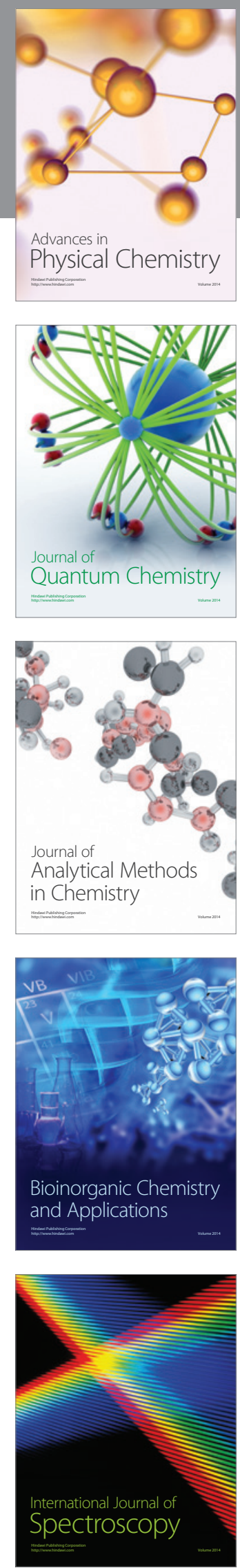